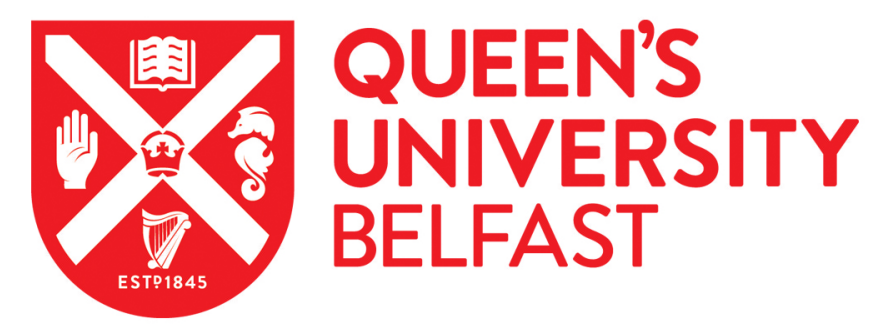

\title{
An optimised milk testing protocol to ensure accurate enumeration of viable Mycobacterium avium subsp. paratuberculosis by the PMS- phage assay
}

Foddai, A. C. G., \& Grant, I. R. (2015). An optimised milk testing protocol to ensure accurate enumeration of viable Mycobacterium avium subsp. paratuberculosis by the PMS-phage assay. International Dairy Journal, 51, 16-23. https://doi.org/10.1016/j.idairyj.2015.07.004

\section{Published in:}

International Dairy Journal

\section{Document Version:}

Peer reviewed version

Queen's University Belfast - Research Portal:

Link to publication record in Queen's University Belfast Research Portal

\author{
Publisher rights \\ (C) 2015, Elsevier. \\ Licensed under the Creative Commons Attribution-NonCommercial-NoDerivatives 4.0 International http://creativecommons.org/licenses/by- \\ nc-nd/4.0/ which permits distribution and reproduction for non-commercial purposes, provided the author and source are cited.
}

\section{General rights}

Copyright for the publications made accessible via the Queen's University Belfast Research Portal is retained by the author(s) and / or other copyright owners and it is a condition of accessing these publications that users recognise and abide by the legal requirements associated with these rights.

Take down policy

The Research Portal is Queen's institutional repository that provides access to Queen's research output. Every effort has been made to ensure that content in the Research Portal does not infringe any person's rights, or applicable UK laws. If you discover content in the

Research Portal that you believe breaches copyright or violates any law, please contact openaccess@qub.ac.uk. 


\section{Accepted Manuscript}

An optimised milk testing protocol to ensure accurate enumeration of viable Mycobacterium avium subsp. paratuberculosis by the PMS-phage assay

Antonio C.G. Foddai, Irene R. Grant

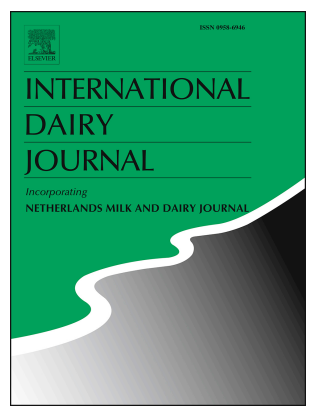

PII:

S0958-6946(15)00140-5

DOI:

10.1016/j.idairyj.2015.07.004

Reference: $\quad$ INDA 3857

To appear in: International Dairy Journal

Received Date: 4 April 2015

Revised Date: 11 July 2015

Accepted Date: 12 July 2015

Please cite this article as: Foddai, A.C.G., Grant, I.R., An optimised milk testing protocol to ensure accurate enumeration of viable Mycobacterium avium subsp. paratuberculosis by the PMS-phage assay, International Dairy Journal (2015), doi: 10.1016/j.idairyj.2015.07.004.

This is a PDF file of an unedited manuscript that has been accepted for publication. As a service to our customers we are providing this early version of the manuscript. The manuscript will undergo copyediting, typesetting, and review of the resulting proof before it is published in its final form. Please note that during the production process errors may be discovered which could affect the content, and all legal disclaimers that apply to the journal pertain. 
1 An optimised milk testing protocol to ensure accurate enumeration of viable

2 Mycobacterium avium subsp. paratuberculosis by the PMS-phage assay

7 Antonio C. G. Foddai, Irene R. Grant*

8

11 Institute for Global Food Security, School of Biological Sciences, Queen's University

12 Belfast, Medical Biology Centre, 97 Lisburn Road, Belfast BT9 7BL, Northern

13 Ireland, United Kingdom.

14

15

16

17

18

${ }^{*}$ Corresponding author. Tel.: +44 2890972109

19

E-mail address: i.grant@qub.ac.uk (I. R. Grant)

20

21

22 
Abstract

25

There is interest in determining levels of Mycobacterium avium subsp.

paratuberculosis (MAP) contamination in milk. The optimal sample preparation for

raw cows' milk to ensure accurate enumeration of viable MAP by the peptidemediated magnetic separation (PMS)-phage assay was determined. Results indicated that milk samples should be refrigerated at $4{ }^{\circ} \mathrm{C}$ after collection and MAP testing should commence within $24 \mathrm{~h}$, or samples can be frozen at $-70^{\circ} \mathrm{C}$ for up to one month without loss of MAP viability. Use of Bronopol is not advised as MAP viability is affected. The vast majority (> 95\%) of MAP in raw milk sedimented to the pellet upon centrifugation at $2500 \times g$ for $15 \mathrm{~min}$, so this milk fraction should be tested. De-clumping of MAP cells was most effectively achieved by ultrasonication of the resuspended milk pellet on ice in a sonicator bath at $37 \mathrm{kHz}$ for 4 min in 'Pulse'

37 mode.

38

39

40 


\section{Introduction}

Due to its possible association with various human conditions, such as

Crohn's disease and ulcerative colitis (Pierce, 2010) and Type 1 diabetes (Rosu et al., 2009), the presence of viable Mycobacterium avium subsp. paratuberculosis (MAP) cells in milk and dairy products is viewed as a potential food safety issue. MAP is the causative agent of Johne's disease, a contagious, chronic and sometimes fatal infection that primarily affects the small intestine of domestic ruminants such as cattle, sheep and goats (Stabel, 1998). Dairy cattle infected by MAP can shed live organisms in both milk and faeces, so potentially bulk milk could be contaminated either directly or indirectly by this bacterium. Whilst uncertainty remains about the public health/food safety significance of MAP, it would be prudent to monitor milk for presence of MAP to assess levels of contamination and hence potential for human exposure. The general desire is that our food should come from disease-free (including Johne's disease-free) animals (Regulation (EC) No 853/2004; European Parliament, 2004).

There is interest amongst dairy producers and processors to identify a rapid method that could be adopted to detect the presence of viable MAP in raw milk or dairy products. Whilst a number of conventional and quantitative PCR methods, able to detect and estimate numbers of MAP in milk have been developed in recent years (Timms, Gehringer, Mitchel, Daskalopoulos, \& Neilan, 2011), the problem remains of differentiating whether a PCR positive result is due to DNA from viable or dead cells (Hanna, Connor, \& Wang, 2005). More recently, use of a phage-based test (FASTPlaqueTB ${ }^{\mathrm{TM}}$ assay, Biotec Laboratories Limited, Ipswich), as a quicker alternative to culture, for rapid detection of viable MAP was described (Stanley et al., 
2007); its application to test naturally infected milk and milk products was

subsequently reported (Botsaris, Liapi, Kakogiannis, Dodd, \& Rees, 2013; Botsaris

et al., 2010). This phage amplification method exploits the ability of a

mycobacteriophage to replicate and amplify only within viable mycobacterial cells.

The number of viable cells can be quickly estimated within 24-48 $\mathrm{h}$ based on the count of plaques (lysed areas) produced when infected cells burst in a lawn of Mycobacterium smegmatis (indicator) cells in an agar plate. We have previously optimised the original FASTPlaqueTB ${ }^{\mathrm{TM}}$ test conditions to maximise detection sensitivity and achieve accurate enumeration (Foddai, Elliott, \& Grant, 2009). A magnetic separation step using paramagnetic beads coated with two MAP-specific peptide binders (aMp3 and aMptD; Stratmann, Dohmann, Heinzmann, \& Gerlach, 2006; Stratmann, Strommenger, Stevenson, \& Gerlach, 2002) was introduced before the phage assay to add specificity for MAP (Foddai, Elliott, \& Grant, 2010b), since the phage involved has a broader host range (Rybniker, Kramme, \& Small, 2006). The peptide-mediated magnetic separation (PMS) both captures and concentrates MAP cells, separating them from non-target microorganisms and other possible inhibitors, thereby increasing the specificity and sensitivity of the subsequent phage assay.

In light of the possibility of the PMS-phage assay being adopted by the dairy industry for milk testing, certain aspects of the milk testing protocol being applied at Queen's University Belfast were investigated to ensure that milk sample storage and preparation before testing were optimal. The following were examined: a) effect of milk storage conditions prior to commencement of testing on the viability of MAP cells, and identification of the best milk storage conditions to be applied when immediate analysis of milk samples is not possible; b) the partitioning of MAP to milk 
91 pellet, cream and whey fractions after centrifugation, to identify which milk fraction should be tested to most accurately determine MAP contamination levels; and c) potential to introduce a de-clumping step before PMS to maximise accuracy of MAP counts obtained with the phage assay. The optimised phage assay was previously demonstrated to be a useful research tool for studies involving milk spiked with pure cultures of MAP (Foddai, Elliott, \& Grant, 2010a), as it provides quantitative results for viable cells within $24 \mathrm{~h}$. Therefore, the optimised phage assay was principally used throughout this study, although conventional culture on solid agar and qPCR were employed in some experiments to supplement or confirm phage assay results.

\section{Materials and methods}

\subsection{Bacterial strains}

Four MAP strains, including two type strains (ATCC 19698 and NCTC 8578) and two milk isolates (796PSS and 806R; Grant, Ball, \& Rowe, 2002), were grown in a shaker incubator for $4-6$ weeks at $37^{\circ} \mathrm{C}$ to statio nary phase in Middlebrook $7 \mathrm{H} 9$ broth containing 10\% OADC supplement (both from Difco) and $2 \mu \mathrm{gL}^{-1}$ mycobactin J (Synbiotics Europe SAS, Lyon, France). Cultures on solid agar for comparison of colony counts (cfu mL ${ }^{-1}$ ) with plaque counts (pfu mL ${ }^{-1}$ ) achieved by phage assay were obtained by spreading appropriate dilutions of Mycobacterium avium subsp. paratuberculosis onto Herrold's egg yolk medium (comprised of $9 \mathrm{~g}$ bacteriological peptone, $4.5 \mathrm{~g}$ sodium chloride, $15.3 \mathrm{~g}$ bacteriological agar, $2.7 \mathrm{~g}$ beef extract, $4.1 \mathrm{~g}$ sodium pyruvate, $27 \mathrm{~mL}$ glycerol, $5 \mathrm{~mL} 2 \%$ malachite green, $100 \mathrm{~mL}$ sterile egg yolk, $2 \mathrm{mg} \mathrm{L}^{-1}$ mycobactin J) and no antibiotics (HEYM). Agar plates were wrapped in 
116 Duraseal laboratory sealing film (Diversified Biotech, MA, USA) and incubated at 37

$117{ }^{\circ} \mathrm{C}$ for 4-6 weeks before counting colonies. Mycobacterium smegmatis $\mathrm{mc}^{2} 155$, to

118 be used as fast-growing sensor cells for the phage assay (see below) was cultured

119 for $2-3$ days at $37^{\circ} \mathrm{C}$ to stationary phase in the sa me $7 \mathrm{H} 9$ medium without the 120 addition of mycobactin $\mathrm{J}$.

121

\subsection{Optimised phage amplification assay}

The optimised phage assay was carried out as previously described by

Foddai et al. (2009). Briefly, after a previous overnight incubation of samples at 37

${ }^{\circ} \mathrm{C}$ in $1 \mathrm{~mL}$ of $7 \mathrm{H} 9$ medium containing $2 \mathrm{~m} \mathrm{M} \mathrm{CaCl}_{2}, 100 \mu \mathrm{L}$ D29 mycobacteriophage $\left(10^{8} \mathrm{pfu} \mathrm{mL}^{-1}\right)$ was added to samples before incubation at $37^{\circ} \mathrm{f}$ or $2 \mathrm{~h}$ during which, particularly post-PMS samples, were shaken periodically every 20-30 min to keep uniform resuspension of paramagnetic beads. Virucide (100 mM ferrous ammonium sulphate (FAS, Sigma), $100 \mu \mathrm{L}$ ) was then added, samples were mixed thoroughly by accurate inverting and rolling (10 $\mathrm{min}$ at room temperature) in order to inactivate all exogenous seed phage before addition of $5 \mathrm{~mL} 7 \mathrm{H} 9$ medium containing $2 \mathrm{mM} \mathrm{CaCl}_{2}$. The samples were returned to the incubator at $37^{\circ} \mathrm{C}$ for a further 90 min before after incubation of plates at $37^{\circ} \mathrm{C}$ overnight. 
PMS was performed on $1 \mathrm{~mL}$ of sample using $5 \mu \mathrm{L}$ biotinylated-aMp3 peptideand $5 \mu \mathrm{L}$ biotinylated-aMptD peptide-coated MyOne ${ }^{\mathrm{TM}}$ Tosylactivated Dynabeads $\AA$ (Life Technologies), prepared in-house as described previously (Foddai et al., 2010b). Magnetic separation was carried out using the Dynal BeadRetriever (Life Technologies) as described previously (Foddai et al., 2010b). Magnetic capture was carried out for 30 min at room temperature under continuous mixing, followed by two washes in $1 \mathrm{~mL}$ Phosphate buffered saline (PBS) containing 0.05\% Tween 20 (PBST20, Sigma), and final resuspension of the beads in $1 \mathrm{~mL} 7 \mathrm{H} 9$ broth containing $10 \%$ OADC and $2 \mathrm{mM} \mathrm{CaCl}_{2}$. For experiments involving PMS of spiked raw milk samples, 7H9 medium was also supplemented with NOA Antimicrobial Supplement (Product code 3A201N-300, Abtek Biological Ltd, Liverpool UK; final concentrations per $\mathrm{mL}^{-1}$ of broth: Nystatin $50 \mathrm{IU}$, Oxacillin $2 \mu \mathrm{g}$, Aztreonam $30 \mu \mathrm{g}$ ). NOA inhibited growth of any milk bacteria adhering to the paramagnetic beads after PMS without impacting viability of the MAP cells, or affecting subsequent phage assay.

The ultrasonic cleaning unit employed in this set of experiments was the Ultrasonic PH 30 (Fisher Scientific Ltd), which has two ultrasonic frequencies (37 $\mathrm{kHz}$ and $80 \mathrm{kHz}$ ) and three operation modes (Sweep, Pulse, Degas). Initially, $2 \mathrm{~mL}$ aliquots of broth suspensions containing approximately $10^{5}-10^{6} \mathrm{MAP}$ pfu $\mathrm{mL}^{-1}$ were processed through different ultrasonication treatments applied at ambient temperature $\left(20-21^{\circ} \mathrm{C}\right)$, using the three operation m odes at 37 and $80 \mathrm{kHz}$, for increasing time periods ( 0 to $5 \mathrm{~min}$ ). Conventional de-clumping method consisting of vortexing samples with five sterile $3 \mathrm{~mm}$ glass beads for $2 \mathrm{~min}$, routinely used at 
165 Queen's University Belfast (Rowe, Grant, Dundee, \& Ball, 2000) to disperse clumps of MAP cells, was included as the control treatment for each experiment. Once the most promising ultrasonication setting had been established, the effect of ultrasonication treatment of samples on ice (suggested by Schleig et al., 2005), rather than directly in water bath at ambient temperature, was also evaluated. The effect of each de-clumping treatment was evaluated by comparing pfu, or cfu, counts obtained before and after treatment.

To investigate the potential for MAP cells to reclump quickly in samples not immediately processed after ultrasonication, $2 \mathrm{~mL}$ broth and whole UHT milk suspensions of four MAP strains containing approximately $10^{5}-10^{6}$ cells $\mathrm{mL}^{-1}$ were de-clumped by the optimised ultrasonication treatment (identified during course of experiments outlined above), and then incubated for $0 \mathrm{~min}, 15 \mathrm{~min}, 30 \mathrm{~min}, 1 \mathrm{~h}$ and overnight (approximately $18 \mathrm{~h}$ ) in a shaker incubator (100 rpm) at $37^{\circ} \mathrm{C}$ before being processed in duplicate through the phage assay. If pfu counts recorded after each incubation time decreased then this was taken as evidence of re-clumping.

\subsection{Assessment of the fractionation of MAP cells in spiked milk samples upon} centrifugation was used for these experiments. Milk samples (10 mL raw and $50 \mathrm{~mL}$ UHT) were inoculated with broth suspensions of MAP to give an initial concentration of approximately $10^{6}$ pfu $\mathrm{mL}^{-1}$. Samples were centrifuged for $15 \mathrm{~min}$ at 2,500 $\times \mathrm{g}$ in an Eppendorf centrifuge (model 5702) at room temperature to separate three milk 
fractions (cream, whey, pellet). After determining the weight of each milk fraction, samples were de-clumped by optimised ultrasonication and processed immediately through the PMS-phage assay. For the cream and pellet fractions, which had been resuspended in $1 \mathrm{~mL}$ PBS-T20, the number of MAP cells was calculated as pfu counts per entire fraction. For the whey fraction the number of cells was determined by processing $1 \mathrm{~mL}$ of whey through the PMS-phage assay and then correcting the pfu count to take into account the total volume of the original whey fraction. The experiment was carried out in duplicate for each bacterial strain considered.

Quantitative PCR targeting both IS900 and f57 specific target-genes of MAP, used either alone (direct qPCR) or combined with prior PMS (PMS-qPCR), was carried out in parallel with the PMS-phage assay to verify the results obtained. DNA for samples processed through direct qPCR was extracted from each milk fraction as described by Hanifian, Khani, Barzegari, and Shayegh (2013). For samples to be processed through qPCR after PMS, bead samples were resuspended in a final volume of $50 \mu \mathrm{L}$ RNAse/DNAse free water and DNA was released from captured cells by heating samples at $95{ }^{\circ} \mathrm{C}$ for $25 \mathrm{~min}$. A $2.5 \mu \mathrm{L}$ aliquot of the supernatant, after centrifugation to sediment beads, was used for each qPCR reaction.

Quantitative PCR targeting both IS900 and f57 was performed as described previously by Donaghy, Johnson, and Rowe (2010). An internal amplification control, labelled with VIC at the 5'-end (EXO IPC - Exogenous Internal Positive Control Reagent) purchased from Applied Biosystems was included for each qPCR reaction. Comparison of EXO-IPC $\mathrm{C}_{\mathrm{T}}$ values obtained in negative test control (NTC) wells and unknown samples was undertaken to assess the possible presence of PCR inhibitors in samples tested. Higher EXO IPC $\mathrm{C}_{\mathrm{T}}$ values in unknown samples relative to NTC wells were taken as indicative of PCR inhibition. Each qPCR reaction was 
performed in a final volume of $25 \mu \mathrm{L}$ including: TaqMan Universal 2X PCR master mix (Applied Biosystems), EXO IPC 10x mix and EXO IPC 10× DNA (Applied

Biosystems), $10 \mu \mathrm{M}$ of each forward and reverse primer and $5 \mu \mathrm{M}$ of specific probe (Donaghy et al., 2010), and $2.5 \mu \mathrm{L}$ template DNA. A calibration curve with DNA

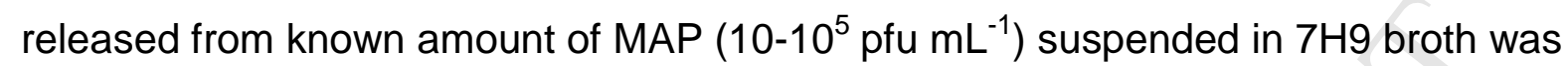
included with each qPCR run to allow quantification of numbers detected. qPCR reactions were performed using an Eco ${ }^{\mathrm{TM}}$ Real-Time PCR system (Illumina, Inc) with the following thermal cycling conditions: stage $1: 50^{\complement} \mathrm{C}$ for $2 \mathrm{~min}$; stage $2: 95{ }^{\circ} \mathrm{C}$ for $10 \mathrm{~min}$ and stage 3 (40 cycles): $95^{\circ} \mathrm{C}$ for $15 \mathrm{~s}$ and $60^{\circ} \mathrm{C}$ for $1 \mathrm{~min}$.

\subsection{Assessment of the effect of refrigeration, freezing, and use of preservative on} numbers of viable MAP in milk

$$
\text { Whole UHT milk samples spiked with moderate }\left(\sim 10^{4} \mathrm{cfu} 50 \mathrm{~mL}^{-1}\right) \text { and low }
$$
levels $\left(\sim 10^{2}\right.$ cfu $\left.50 \mathrm{~mL}^{-1}\right)$ of the four strains were processed through the PMS-phage assay applied after centrifugation at 2,500 $\times \mathrm{g}$, resuspension of milk pellet fraction in $1 \mathrm{~mL}$ PBS-T20 and de-clumping by optimised ultrasonication. Samples were divided between three storage categories: 1) fresh - samples processed immediately or after overnight at $4{ }^{\circ}$; 2) frozen - samples tested after 1 week, 2 weeks and 1 month at $70^{\circ} \mathrm{C}$; and 3) chemically preserved - milk samples t reated with a milk preservative [1 $\mathrm{mL}$ of a solution containing $1 \%$ Bronopol (Sigma-Aldrich, UK) added to $50 \mathrm{~mL}$ spiked

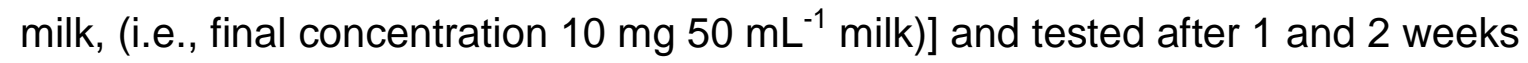
storage at $4{ }^{\mathrm{C}}$. Duplicate milk samples were tested for each strain under all experimental conditions. Counts (pfu $50 \mathrm{~mL}^{-1}$ ) were compared for each storage condition relative to the starting bacterial spiking level; a decrease in pfu count was 
considered to be an indication of loss of viability by a proportion of MAP cells present.

242

\subsection{Statistical analysis of results}

The statistical significance of the increase or reduction in plaque (pfu) and colony (cfu) counts observed for each treatment applied to broth and milk samples inoculated with viable MAP was assessed by a paired $t$ test (Instat 3; GraphPad, La Jolla, CA); differences with $P<0.05$ were considered significant. Correlation

between numbers of MAP detected through PMS-phage assay and qPCR was assessed using linear regression analysis (Microsoft Excel).

\section{Results}

\subsection{Use of ultrasonication to disperse MAP clumps}

To determine the optimal ultrasonication treatment to disperse clumps of MAP

cells various treatments were studied. Of the different sonication settings applied in a sonicator bath at room temperature, the greatest degree of de-clumping was consistently achieved in samples processed through ultrasonication using Pulse mode; mean $\log _{10}$ increase in pfu counts for MAP strains ATCC 19698 and NCTC 8578 were $0.17 \pm 0.02$ and $0.23 \pm 0.08(P<0.01)$, respectively (Fig. $1 \mathrm{~A})$.

Corresponding increases observed for samples de-clumped by vortexing samples with glass beads were $0.35 \pm 0.06$ and $0.44 \pm 0.04$, respectively $(P<0.001)$. Generally similar trends in terms of effects of each de-clumping treatment were observed with 
cfu counts on HEYM (Fig. 1B), although $\log _{10}$ increases tended not to be as large as observed with pfu $\mathrm{mL}^{-1}$ results.

Significantly greater de-clumping was achieved when ultrasonication was applied to samples on ice in the sonicator bath $(P<0.001)$, rather than directly in the water bath at ambient temperature (Fig. 2A). This was the case for all strains with the exception of MAP strain 806R which showed considerable variability in counts (large error bar) when vortexed with glass beads. Mean $\log _{10}$ increase in pfu counts observed for two type strains (ATCC 19698 and NCTC 8578) and two milk isolates (796PSS and $806 \mathrm{R}$ ) were $0.90 \pm 0.08,0.87 \pm 0.14,0.36 \pm 0.03$ and $0.51 \pm 0.08$, respectively, with overall mean of $0.66 \pm 0.08$. The corresponding mean $\log _{10}$ increase in pfu counts observed for samples de-clumped by vortexing with glass beads was lower for each MAP strain $(0.60 \pm 0.10,0.44 \pm 0.04,0.20 \pm 0.02$ and $0.37 \pm 0.30$, respectively, with overall mean $\log _{10}$ increase in pfu of $\left.0.40 \pm 0.12, P<0.01\right)$. No significant increase in pfu counts was observed for samples subjected to extended incubation on ice for 5 or $10 \mathrm{~min}$ before the ultrasonication treatment $(P>0.05$ in both cases). Generally, similar trends in terms of effects of each de-clumping treatment were observed with cfu counts on HEYM (Fig. 2B), although $\log _{10}$ increases tended not to be as large as observed with pfu $\mathrm{mL}^{-1}$ results.

The possibility of MAP cells re-clumping quickly after sonication treatment was estimated by comparing counts recorded from samples enumerated at various times after de-clumping. Mean pfu counts recorded for spiked milk samples immediately after de-clumping and after each incubation time did not vary significantly $(P=0.96)$, suggesting that no re-clumping occurred (Fig. 3A). Similar results were obtained for MAP broth cultures processed through the phage assay started after $0 \mathrm{~min}, 15 \mathrm{~min}, 30 \mathrm{~min}$ and $1 \mathrm{~h}(P=0.06$, Fig. 3B). However, a significant 
290 increase in pfu $\mathrm{mL}^{-1}$ counts $\left(\sim 2 \log _{10}\right)$ was consistently recorded for MAP broth

291

292

293

294

295

296

297

298

299

300

301

302

303

304

305

306

307

308

cultures incubated overnight in $7 \mathrm{H} 9-\mathrm{OADC}-2 \mathrm{mM} \mathrm{CaCl}_{2}$ at $37^{\circ} \mathrm{C}$ before the phage assay commenced (Fig. 3B). This substantial increase in pfu $\mathrm{mL}^{-1}$ was not unexpected, as it is consistent with our previous finding (Foddai et al., 2009) that there is enhanced phage infection of MAP cells and increased pfu counts when they have been incubated overnight in the presence of $2 \mathrm{mM} \mathrm{CaCl}_{2}$.

\subsection{Fractionation of MAP cells within milk upon centrifugation}

Upon centrifugation of 10 or $50 \mathrm{~mL}$ volumes of MAP spiked milk at $2500 \times \mathrm{g}$ for 15 min, the vast majority of the MAP cells in both raw and UHT homogenised milk were consistently recovered from the milk pellet. Mean $\log _{10}$ pfu observed from both homogenised and non-homogenised milk inoculated with various MAP strains was $6.28 \pm 0.25$ and $6.38 \pm 0.06$, respectively, corresponding to approximately $81.53 \pm 5.76 \%$ and $96.7 \pm 1.7 \%$, respectively, of the initial inocula. The percentage of bacterial cells recovered from the milk whey fraction ranged from 11.4 to $25.6 \%$ (overall mean $18.4 \pm 5.8 \%$ ) for UHT homogenised milk and 0.4 to $2.9 \%$ (mean $1.6 \pm 0.21 \%)$ for raw milk. The percentage of MAP recovered from the cream was lower than expected, on the basis of previous studies, in both cases; overall mean observed was $1.6 \pm 0.21 \%$ for whole raw and $0.06 \pm 0.02 \%$ for UHT homogenised milk. No significant difference in fractionation between MAP strains employed to spike raw and UHT milk was observed $(P>0.05)$.

Numbers of MAP in each milk fraction estimated via direct-qPCR were more variable than PMS-qPCR, but similar trends in numbers of MAP cells per fraction were generally observed. Lack of sensitivity was observed when QPCR was applied 
alone on DNA extracted from each raw milk fraction after centrifugation; $\mathrm{C}_{\mathrm{T}}$ values obtained from EXO IPC assay from samples were generally higher than those obtained from negative test control (NTC) samples indicating the presence of PCR inhibitors. Numbers of MAP estimated through IS900 and f57 direct-qPCR were consistently lower (by $1-2 \log _{10}$ ) than corresponding values achieved through PMSphage assay and PMS-qPCR $(P<0.05$ and $P<0.01$, respectively). Best correlation was observed between qPCR and phage assay results $\left(r^{2}=0.8568\right.$ for IS900 qPCR and $r^{2}=0.7631$ for 557 qPCR) when PMS was applied before QPCR for both types of spiked milk samples (Fig. 4A,B). No significant variance of EXO-IPC $C_{T}$ values for all post-PMS DNA samples relative to NTC wells was observed, indicating apparent absence of PCR inhibitors in these samples.

\subsection{Effect of various milk storage conditions pre-testing on MAP viability}

The effect of refrigeration, freezing, and use of preservative on numbers of viable MAP in milk was evaluated. Counts (pfu) detected from samples processed immediately or after one overnight at $4{ }^{\circ} \mathrm{C}$ were $\operatorname{sim}$ ilar $(P>0.05$, Fig. 5A,B), suggesting that milk analysis can be performed on fresh or overnight refrigerated milk samples without adverse effect on MAP counts. Minimal reduction in numbers of MAP detected $(P>0.05)$ was observed from samples refrigerated for 3 days before milk analysis. Mean $\log _{10}$ decrease in pfu counts for both moderate-spiked (Fig. 5A) and low-spiked (Fig. 5B) milk samples was $0.41 \pm 0.08$ and $0.15 \pm 0.10$, respectively. No adverse effect on pfu counts $(P>0.05)$ was also observed from milk samples previously frozen at $-70{ }^{\circ} \mathrm{C}$ for 1 or 2 weeks and 1 month before testing. $\log _{10}$ decrease in pfu counts ranged from $0.29 \pm 0.23$ to $0.52 \pm 0.20 \log _{10}$ for moderate (Fig. 
$5 A$ ), and from $0.01 \pm 0.20$ and $0.20 \pm 0.24$ for low-spiked level (Fig. 5B), suggesting

minimal impact of frozen storage at $-70^{\circ} \mathrm{C}$ on viabi lity of MAP cells. In contrast, addition of Bronopol, as a milk preservative, in combination with refrigeration at $4{ }^{\circ} \mathrm{C}$ for 1 and 2 weeks was found to severely impact viability of MAP cells. In the case of one MAP strain (806R) viability was so adversely affected that no viable MAP were detected in low spiked milk when testing was preceded by refrigeration for 2 weeks in the presence of Bronopol (Fig. 5B). Counts (pfu) observed for milk samples processed after 1 and 2 weeks were consistently 1-2 $\log _{10}$ lower than those observed from fresh samples (Fig. 5A,B). Mean $\log _{10}$ decrease in pfu counts observed in moderate and low-spiked milk samples was $1.96 \pm 0.38$ and $1.04 \pm 0.20$ after 1 week $(P<0.01)$ and $2.25 \pm 0.56$ and $1.70 \pm 0.40$ after 2 weeks $(P<0.001)$, respectively.

\section{Discussion}

The objective of this study was to develop an optimised protocol for sample processing and PMS-phage assay testing of raw milk samples to ensure rapid detection and accurate enumeration of viable MAP, so a number of aspects of the current milk testing protocol were investigated. The first part of the study focused on the development of a non-invasive de-clumping method to maximise accuracy of MAP cells obtained through PMS-phage assay. Due to the hydrophobic nature of its cell wall, MAP cells tend to aggregate in clumps, the presence of which in test milk samples can lead to underestimates of MAP numbers by a factor of 100-1000 cells (Klijn, Herrewegh, \& de Jong, 2001; Pearce et al., 2001). Various de-clumping 
options, including repeated syringing (Keswani \& Frank, 1998; Sung \& Collins, 1998), vortexing with glass beads (Rowe et al., 2000), and sonication (Chiodini \& Hermon-Taylor, 1993; Stabel, Steadham, \& Bolin, 1997) have previously been applied in the preparation of MAP inocula by other researchers. The method routinely applied at Queen's University Belfast involves vortexing the MAP culture with five sterile $3 \mathrm{~mm}$ glass beads for $2 \mathrm{~min}$. However, the sterile glass beads would generally be added to $7 \mathrm{H} 9$ broth at the time of preparation, not at the point of declumping, which would be the case in the context of milk testing. Introduction of glass beads to each test milk sample would be laborious and may increase the risk of introducing exogenous MAP DNA to the milk sample, if this approach were to be taken. A similar situation would exist in the case of syringing, the use of which would also require extra costs for additional sterile consumables. For these reasons, only treatment of samples in sealed tubes in a sonicator bath would seem to be a realistic proposition. The impact of different sonicator bath power settings and treatment temperatures and times on the viability of MAP cells was evaluated. Amongst the different sonication settings involving low-frequency ultrasound treatment (37 and $80 \mathrm{kHz}$ ) at ambient temperature, no significant de-clumping was observed. A small increase in MAP numbers compared to vortexing with glass beads (control treatment) suggested a minimal effect on disruption of MAP clumps. With the possible exception of one of the MAP field strains (MAP 806R), ultrasonication at $37 \mathrm{kHz}$ on ice achieved significantly greater de-clumping of MAP suspensions than the control method (vortexing with glass beads). When grown in broth, 806R forms particularly large aggregates of cells and generally proves difficult to de-clump and achieve a visually uniform suspension; the large error bars for vortexing of MAP 806R (Fig. 2A) is reflective of this situation. Overall, no adverse effect of de- 
clumping by ultrasonication at $37 \mathrm{kHz}$ in Pulse mode for 4 min on the viability of MAP cells was observed.

Milk samples to be tested for MAP generally require initial centrifugation to reduce large volumes $(20-50 \mathrm{~mL})$ to a $1 \mathrm{~mL}$ test volume appropriate for PMS. The PMS-phage assay and qPCR results obtained during the present study indicate that the milk pellet is the location of maximal numbers of MAP after centrifugation of a milk sample at 2,500 $\times g$ for $15 \mathrm{~min}$ at ambient temperature. Mean percentage recovery of MAP in the pellet estimated based on pfu counts for spiked homogenised UHT milk and spiked raw milk were $>80 \%$ and $95 \%$, respectively. Considerably lower proportions of MAP cells were generally recovered from the whey $(18.4 \%$ and $1.6 \%$ for spiked homogenised UHT and raw milk, respectively) and cream $(0.06 \%$ and $1.6 \%$ for spiked homogenised UHT and raw milk, respectively) fractions. Thus, in the case of raw milk samples negligible numbers of MAP would be lost if the whey and cream fractions were discarded after centrifugation; the picture for homogenised milk seems to be rather different. Comparison of results achieved by the two detection methods showed a better correlation between phage assay and PMSqPCR results than direct qPCR results; some evidence of PCR inhibition was obtained for direct qPCR, but not for PMS-qPCR. PMS was, therefore, confirmed to be an effective method to achieve selective concentration of target cells plus removal of PCR inhibitors from test samples. Two previous fractionation studies carried out on raw milk inoculated with MAP showed that the vast majority of the original inoculum sediment to the milk pellet after centrifugation (Grant, Ball, \& Rowe, 1998; Van Brandt et al., 2010). Another study (Gao, Odumeru, Raymond, \& Mutharia, 2005) reported that MAP cells preferentially partitioned to the cream fraction upon centrifugation, leading to a recommendation that the pellet and cream fractions 
should be combined for MAP testing of milk. The centrifugation conditions adopted by Van Brandt et al. (2010; $974 \times g$ for 36 min at $\left.4^{\circ} \mathrm{C}\right)$ and Gao et al. $(2005 ; 3100 \times$ $g$ for $30 \mathrm{~min}$, temperature not stated) differ from those used by Grant et al. (1998) and in the current study $(2,500 \times g$ for $15 \mathrm{~min}$ at room temperature). In particular, temperature of centrifugation, or temperature of milk at time of centrifugation, may have impacted the differing fractionation profiles observed. When processing raw milks in our laboratory, we purposely allow milk samples to attain ambient temperature before starting to test and always centrifuge at ambient temperature (not at $4^{\circ} \mathrm{C}$ ) to ensure that sedimentation of MAP $\mathrm{c}$ ells to the pellet is maximised. Another important consideration for the establishment of an optimised milk testing protocol was to discover the best milk storage condition to be adopted for milk samples if milk analysis cannot start immediately upon delivery of samples. Raw milk samples for MAP testing are usually collected miles away from the testing laboratory, and refrigeration, use of milk preservatives, or freezing samples are some of the methods used to preserve milk samples after collection or upon delivery. As the phage assay exploits the ability of D29 mycobacteriophage to replicate only within viable mycobacterial cells, maintaining the viability of MAP cells in test samples is critical. To the best of our knowledge, no information is currently available in the literature on how storage conditions including refrigeration, freezing, and use of preservative affect viability of MAP cells in milk. Results of the present study indicate that processing milk on the same day as collection or after overnight storage at $4^{\circ} \mathrm{C}$ are the ideal conditions to maximise detect ion and achieve accurate enumeration of viable MAP cells. If this is not possible, then freezing of milk samples at $-70{ }^{\circ}$ for up to one month could be alternativel y applied with minimal impact on viable MAP counts. In contrast, the addition of milk preservative (Bronopol) to milk 
samples which are then refrigerated for 1 or 2 weeks at $4^{\circ} \mathrm{C}$ weeks should be avoided as these conditions significantly affected viability of MAP; this could lead to underestimation of the number of MAP cells originally present in milk samples, or false negative results if $<10^{2}$ MAP cells are present per $50 \mathrm{~mL}$ milk. Our findings are in general agreement with the literature available on the subject. Use of milk preservatives, particularly Bronopol, have already been reported to cause bacterial membrane damage affecting both Gram-negative (Escherichia coli and Pseudomonas aeruginosa) and Gram-positive (Staphylococcus aureus) bacteria (Shepherd, Waigh, \& Gilbert, 1988; Stretton \& Manson, 1973). This might explain the reduction in bacterial count as observed in our study and in other milk surveys previously carried out (Amores et al., 2010; Pinnow et al., 2001). Freezing of milk samples at $-80^{\circ} \mathrm{C}$ without adverse effect on the via bility of bacterial cells has previously been also reported for other pathogenic bacteria, including coagulasenegative staphylococci and Gram-negative bacilli (Sanchez et al., 2003).

\section{Conclusions}

Milk samples should be refrigerated at $4^{\circ} \mathrm{C}$ after c ollection and MAP testing should commence within $24 \mathrm{~h}$, or, when this is not possible, samples can be frozen at $-70{ }^{\circ} \mathrm{C}$ for up to one month without significant l oss of MAP viability. The vast majority (>95\%) of MAP in raw milk were found to sediment to the pellet fraction upon centrifugation at $2500 \times g$ for $15 \mathrm{~min}$, so this milk fraction should be tested. Declumping of MAP aggregates before PMS is most effectively achieved by ultrasonication of the resuspended milk pellet on ice in a sonicator bath at $37 \mathrm{kHz}$ for 4 min in 'Pulse' mode. Our findings regarding optimal milk storage and preparation 
465

466

467

468

469

470

471

472

473

474

475

476

477

478

479

480

481

482

483

484

485

486

487

488

prior to MAP testing by the PMS-phage assay should theoretically be equally

applicable to milk samples to be cultured; however the effect of chemical

decontaminants on viability of MAP cells that had been previously frozen and thawed would be an additional consideration.

\section{Acknowledgments}

The authors acknowledge financial support from the Nestlé Research Center, Lausanne, Switzerland, to pursue this research.

\section{References}

Amores, J., Sánchez, A., Martín, A.G., Corrales, J.C., Contreras, A., \& de la Fe, C. (2010). Viability of Mycoplasma agalactiae and Mycoplasma mycoides subsp. capri in goat milk samples stored under different conditions. Veterinary Microbiology, 145, 347-350.

Botsaris, G., Liapi, M., Kakogiannis, C., Dodd, C.E.R., \& Rees, C.E.D. (2013). Detection of Mycobacterium avium subsp. paratuberculosis in bulk tank milk by combined phage-PCR assay: Evidence that plaque number is a good predictor of MAP. International Journal of Food Microbiology, 164, 76-80.

Botsaris, G., Slana, I., Liapi, M., Dodd, C., Economides, C., Rees, C., et al. (2010). Rapid detection methods for viable Mycobacterium avium subspecies paratuberculosis in milk and cheese. International Journal of Food Microbiology, 141, 87-90. 
Chiodini, R. J., \& Hermon-Taylor, J. (1993). The thermal resistance of Mycobacterium paratuberculosis in raw milk under conditions simulating pasteurization. Journal of Veterinary Diagnostic Investigation, 5, 629-631.

Donaghy, J. A., Johnson, J., \& Rowe, M. T. (2010). Detection of Mycobacterium avium subsp. paratuberculosis in cheese, milk powder and milk using IS900 and F57- based assays. Journal of Applied Microbiology, 110, 479-489.

European Parliament. (2004). Regulation (EC) No 853/2004 of the European Parliament and of the Council, of 29 April 2004, laying down specific hygiene rules for food of animal origin. Official Journal of the European Union L, 139, 55.

Foddai, A., Elliott, C. T., \& Grant, I. R. (2009). Optimization of a phage amplification assay to permit accurate enumeration of viable Mycobacterium avium subsp. paratuberculosis cells. Applied and Environmental Microbiology, 75, 38963902.

Foddai, A., Elliott, C. T., \& Grant, I. R. (2010a). Rapid assessment of the viability of Mycobacterium avium subsp. paratuberculosis after heat treatment, using the optimized phage amplification assay. Applied and Environmental Microbiology, 76, 1777-1782.

Foddai, A., Elliott, C. T., \&Grant, I. R. (2010b). Maximizing capture efficiency and specificity of magnetic separation for Mycobacterium avium subsp. paratuberculosis cells. Applied and Environmental Microbiology, 76, 75507558.

Gao, A., Odumeru, J., Raymond, M., \& Mutharia. L. (2005). Development of improved method for isolation of Mycobacterium avium subsp. 
paratuberculosis from bulk tank milk: effect of age of milk, centrifugation, and decontamination. Canadian Journal of Veterinary Research, 69, 81-87.

515

Grant, I. R., Ball, H. J., \& Rowe, M. T. (1998). Isolation of Mycobacterium paratuberculosis from milk by immunomagnetic separation. Applied and Environmental Microbiology, 64, 3153-3158.

Grant, I. R., Ball, H. J., \& Rowe, M. T. (2002). Incidence of Mycobacterium paratuberculosis in bulk raw and commercially pasteurized cows' milk from approved dairy processing establishments in the United Kingdom. Applied and Environmental Microbiology, 68, 2428-2435.

Hanifian, S., Khani, S., Barzegari, A., \& Shayegh, J. (2013). Quantitative real-time PCR and culture examination of Mycobacterium avium subsp. paratuberculosis at farm level. Veterinary Microbiology, 162, 160-165.

Hanna, S. E., Connor, C. J., \& Wang, H. H. (2005). Real-time polymerase chain reaction for the food microbiologist: technologies, applications, and limitations. Journal of Food Science, 70, 49-53.

Keswani, J., \& Frank, J. F. 1998. Thermal inactivation of Mycobacterium paratuberculosis in milk. Journal of Food Protection, 61, 974-978.

Klijn, N., Herrewegh, A. A., \& de Jong, P. (2001). Heat inactivation data for Mycobacterium avium subsp. paratuberculosis: implications for interpretation. Journal of Applied Microbiology, 91, 697-704.

Pearce, L. E., Truong, H. T., Crawford, R. A., Yate, G. F., Cavaignac, S., \& De Lisle, G. W. (2001). Effect of turbulent-flow pasteurization on survival of Mycobacterium avium subsp. paratuberculosis added to raw milk. Applied and Environmental Microbiology, 67, 3964-3969. 
537

538

539

540

541

542

Pierce, E. S. (2010). Ulcerative colitis and Crohn's disease: is Mycobacterium avium subspecies paratuberculosis the common villain? Gut Pathogens, 2, 21.

Pinnow, C. C., Butler, J. A., Sachse, K., Hotzel, H., Timms, L. L., \& Rosenbusch, R. F. (2001). Detection of Mycoplasma bovis in preservative treated field milk samples. Journal of Dairy Science, 84, 1640-1645.

Rosu, V., Ahmed, N., Paccagnini, D., Gerlach, G., Fadda, G., Hasnain, S.E., et al. (2009). Specific immunoassays confirm association of Mycobacterium avium subsp. paratuberculosis with Type-1 but Not Type-2 diabetes mellitus. PLoS ONE, 4, e4386.

Rowe, M. T., Grant, I. R., Dundee, L., \& Ball, H. J. (2000). Heat resistance of Mycobacterium avium subsp. paratuberculosis in milk. Irish Journal of Agricultural and Food Research, 39, 203-208.

Rybniker, J., Kramme, S., \& Small, P. L. (2006). Host range of 14 mycobacteriophages in Mycobacterium ulcerans and seven other mycobacteria including Mycobacterium tuberculosis-application for identification and susceptibility testing. Journal of Medical Microbiology, 55, $37-42$.

Sanchez, A., Contreras, A., Jiménez, J., Luengo, C., Corrales, J. C., \& Fernández, C. (2003). Effect of freezing goat milk samples on recovery of intramammary bacterial pathogens. Veterinary Microbiology, 94, 71-77.

Schleig, P. M., Buergelt, C. D., Davis, J. K., Williams, E., Monif, G. R. G., \& Davidson, M. K. (2005). Attachment of Mycobacterium avium subspecies paratuberculosis to bovine intestinal organ cultures: method development and strain differences. Veterinary Microbiology, 108, 271-279. 
561 Shepherd, J. A., Waigh, R. D., \& Gilbert, P. (1988). Antibacterial action of 2-bromo-2-

562

563

564

565

566

567

568

569

570

571

572

573

574

575

576

577

578

579

580

581

582

583

584 nitropropane-1,3-diol (bronopol). Antimicrobial Agents Chemotherapy, 32, 1693-1698.

Stabel, J. R. (1998). Johne's disease: a hidden threat. Journal of Dairy Science, 81, 283-288.

Stabel, J. R., Steadham, E. M., \& Bolin, C. A. (1997). Heat inactivation of Mycobacterium paratuberculosis in raw milk: are current pasteurization conditions effective? Applied and Environmental Microbiology, 63, 49754977.

Stanley, E. C., Mole, R. J., Smith, R. J., Glenn, S. M., Barer, M. R., McGowan, M., et al. (2007). Development of a new, combined rapid method using phage and PCR for detection and identification of viable M. paratuberculosis bacteria within 48 h. Applied and Environmental Microbiology, 73, 1851-1857.

Stratmann, J., Dohmann, K., Heinzmann, J., \& Gerlach, G. F. (2006). Peptide aMptD-mediated capture PCR for detection of Mycobacterium avium subsp. paratuberculosis in bulk milk samples. Applied and Environmental Microbiology, 72, 1265-1274.

Stratmann, J., Strommenger, B., Stevenson, K., \& Gerlach, G. F. (2002). Development of a peptide-mediated capture PCR for detection of Mycobacterium avium subsp. paratuberculosis in milk. Journal of Clinical Microbiology, 40, 4244-4250.

Stretton, R. J., \& Manson, T. W. 1973. Some aspects on the mode of action of the antibacterial compound bronopol (2-bromo 2-nitropropane 1,3-diol). Journal of Applied Bacteriology, 36, 61-76. 
585 Sung, N., \& Collins, M. T. (1998). Thermal tolerance of Mycobacterium paratuberculosis. Applied and Environmental Microbiology, 64, 999-1005.

587 Timms, V. J., Gehringer, M. M., Mitchel, H. M., Daskalopoulos, G., \& Neilan, B. A. (2011). How accurately can we detect Mycobacterium avium subsp. paratuberculosis infection. Journal of Microbiological Methods, 85, 1-8.

Van Brandt, L., Coudijzer, K., Vlaemynck, G., Hendrickx, M., Michiels, C., Messens, W., Herman, L., et al. (2010). Localization of Mycobacterium avium subspecies paratuberculosis in artificially inoculated milk and colostrum by fractionation. Journal of Dairy Science, 93, 4722-4729. 


\section{$1 \quad$ Figure legends}

2

3 Fig. 1. Comparison of the de-clumping effects of vortexing with glass beads for 2

$4 \min ($ Control) and three ultrasonication treatments (Pulse Mode at $37 \mathrm{kHz}$ for 2, 3 or

$54 \mathrm{~min})$. Middlebrook $7 \mathrm{H} 9$ broth cultures of various MAP strains containing $10^{5}-10^{6}$

$6 \mathrm{pfu} \mathrm{mL} \mathrm{m}^{-1}$ were placed in a steel basket and processed in a sonicator bath at ambient

7 temperature $\left(20^{\circ} \mathrm{C}\right)$. MAP was enumerated by $(A)$ phag e assay $\left(\mathrm{pfu} \mathrm{mL}^{-1}\right)$ and $(\mathrm{B})$

8 culture on HEYM (cfu mL ${ }^{-1}$ ). The larger the increase in $\log _{10}$ pfu $\mathrm{mL}^{-1}$ observed, the

9 greater the de-clumping effect of the treatment. For each MAP strain results are

10 mean \pm standard deviation of two experiments with duplicate samples per

11 experiment.

Fig. 2. De-clumping effects of ultrasonication (Pulse Mode at $37 \mathrm{kHz}$ for $4 \mathrm{~min}$ ) on ice compared with vortexing with glass beads for 2 min (Control). Middlebrook 7H9 broth cultures of four MAP strains containing $10^{5}-10^{6} \mathrm{pfu} \mathrm{mL}^{-1}$ were processed in a sonicator bath on ice. MAP was enumerated by $(A)$ phage assay (pfu mL $\mathrm{m}^{-1}$ ) and (B) culture on HEYM (cfu mL $\mathrm{m}^{-1}$ ). The larger the increase in $\log _{10}$ pfu or cfu $\mathrm{mL}^{-1}$ observed, the greater the de-clumping effect of the treatment. For each MAP strain results are mean \pm standard deviation of two experiments with duplicate samples per experiment. Bars represent (left to right): vortexing with glass beads for 2 min (control, $\mathbf{\square}$ ), ultrasonication on ice at $37 \mathrm{kHz}$ for $4 \mathrm{~min}(\boldsymbol{\square})$, incubation for 5 min on ice before ultrasonication on ice at $37 \mathrm{kHz}$ for $4 \mathrm{~min}(\boldsymbol{\square})$, and incubation for $10 \mathrm{~min}$ on ice before ultrasonication on ice at $37 \mathrm{kHz}$ for $4 \min (\boldsymbol{\square})$. 
Fig. 3. Investigation of possible re-clumping of MAP cells in (A) spiked milk samples and (B) Middlebrook 7H9 broth cultures after ultrasonication treatment. Samples were processed through the phage amplification assay immediately after ultrasonication (0 $\mathrm{min}$, ) and at increasing times (15 min, ; $30 \mathrm{~min}$, $\mathbf{\square} ; 1 \mathrm{~h}, \mathbf{\square}$; overnight at $\left.37^{\circ} \mathrm{C}, \mathbf{\square}\right)$ post-ultrasonication. No significant decrease in MAP count, which would have been indicative of re-clumping, was observed. For each MAP duplicate samples per experiment.

Fig. 4. Relationship between MAP counts obtained by PMS-phage assay and corresponding numbers of MAP estimated by (A) PMS-IS900 qPCR and (B) PMSf57 qPCR for cream (white), whey (grey) and pellet (black) fractions after centrifugation of $10 \mathrm{~mL}$ raw milk (circles) and $50 \mathrm{~mL}$ homogenised UHT milk (diamonds) originally spiked with approximately $10^{6}$ pfu MAP $\mathrm{mL}^{-1}$. Each data point represents the mean of two samples.

Fig.5. Impact of pre-testing storage conditions on numbers of viable MAP in milk samples spiked with $10^{4} \mathrm{pfu} 50 \mathrm{~mL}^{-1}$. Four different MAP strains were used for spiking experiments. Milk samples were processed through the PMS-phage assay immediately after spiking and after different pre-testing storage conditions: $(A)$ refrigeration at $4^{\circ} \mathrm{C}$, with and without addition of Bronopol preservative, and (B) freezing at $-70^{\circ} \mathrm{C}$. For each MAP strain results are mean \pm standard deviation of two experiments with duplicate samples per experiment. Bars represent (left to right):

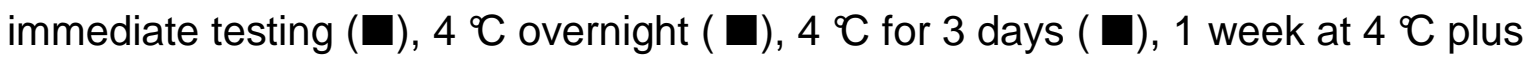


49 Bronopol (ם), 2 weeks at $4{ }^{\circ} \mathrm{C}$ plus Bronopol ( $\left.\mathbf{\square}\right), 1$ week at $-70{ }^{\circ} \mathrm{C}(\boldsymbol{\square}), 2$ weeks at $5070^{\circ} \mathrm{C}(\square)$, and 1 month at $-70^{\circ} \mathrm{C}(\mathrm{Q}$.

51

52 

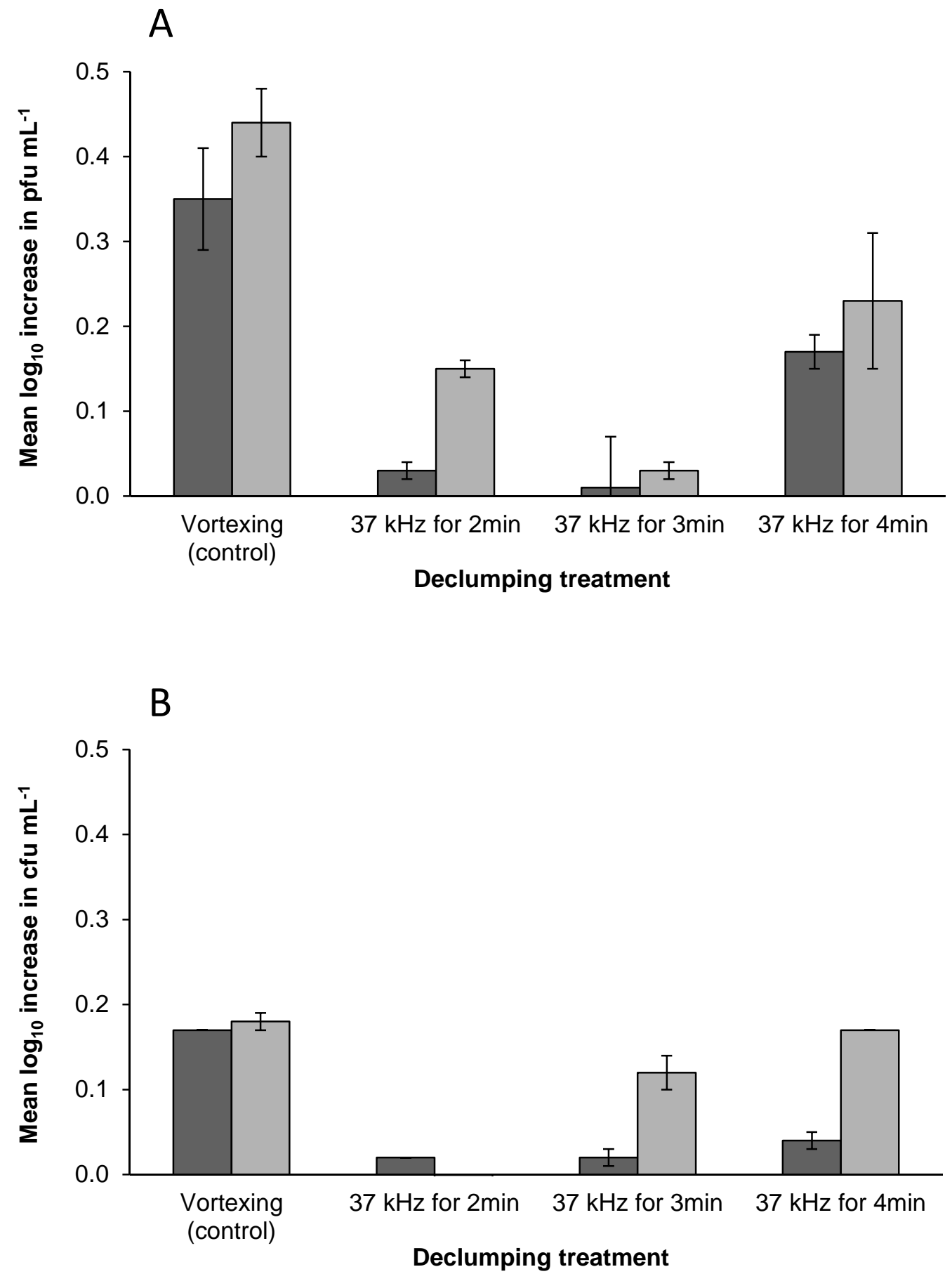

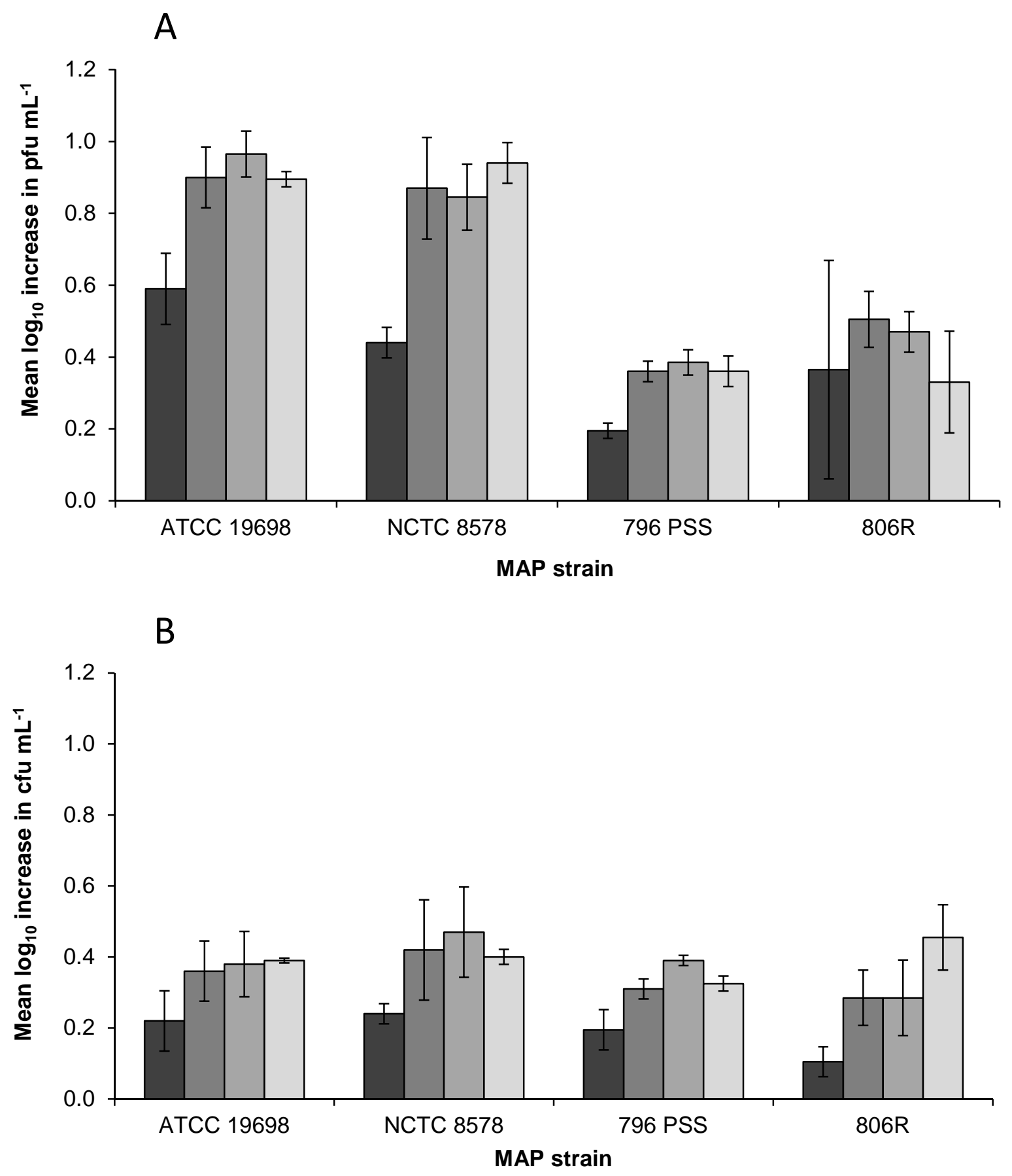

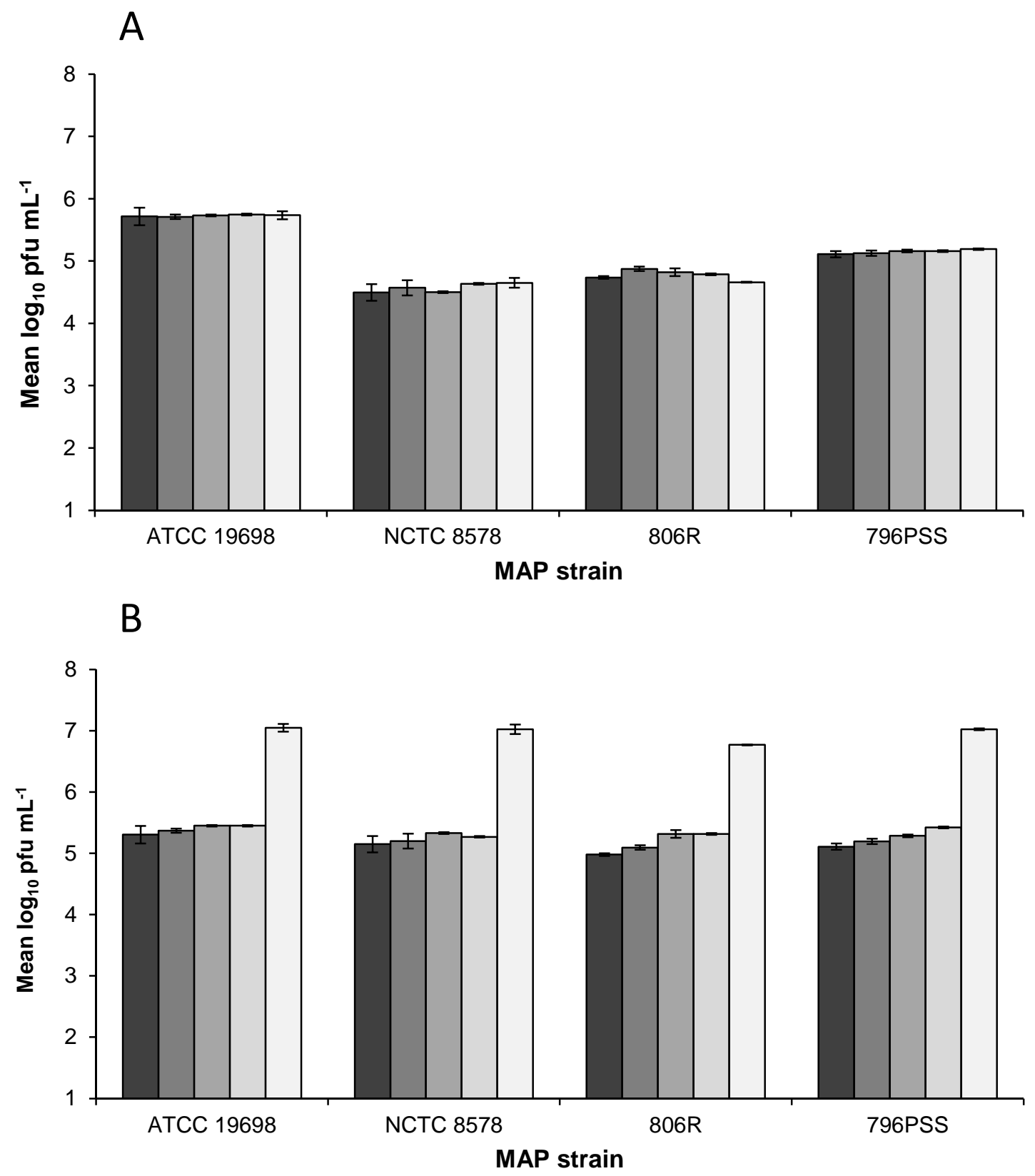

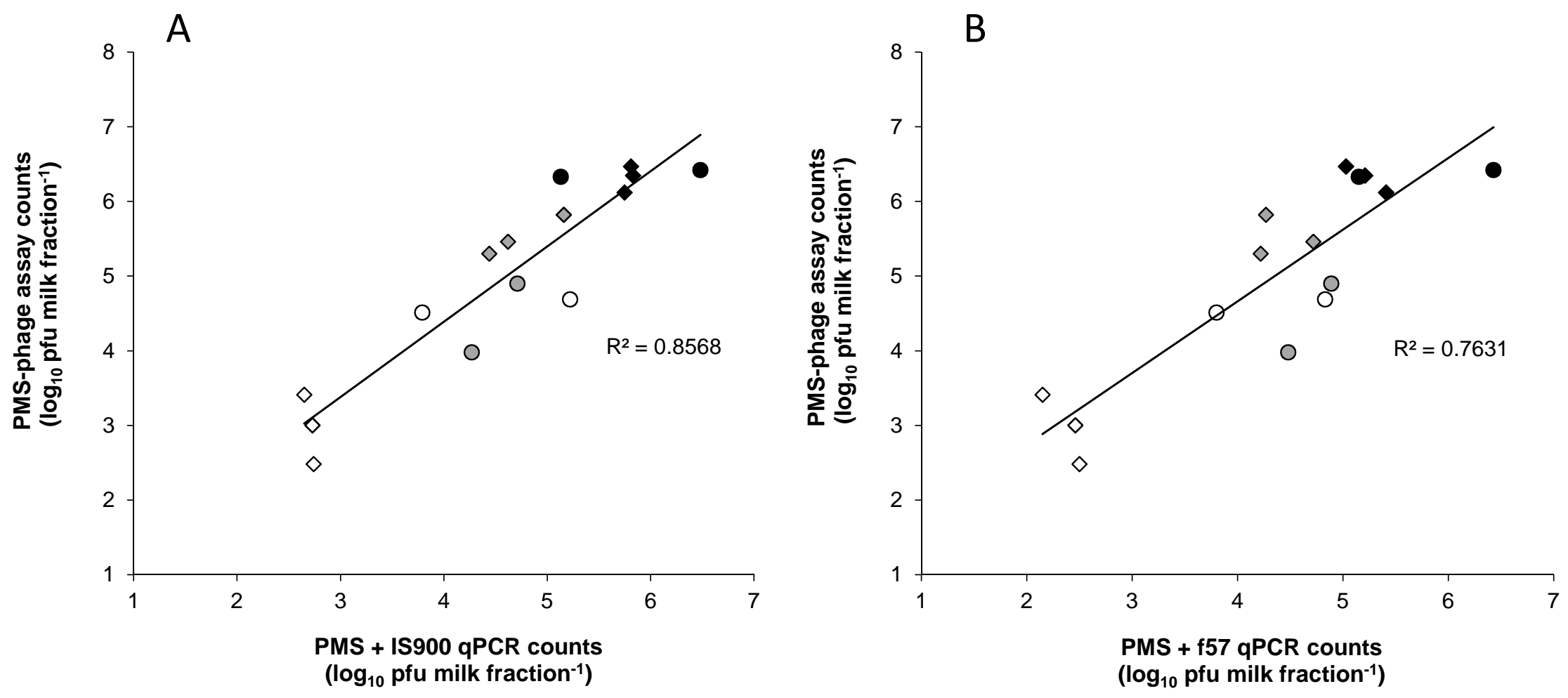

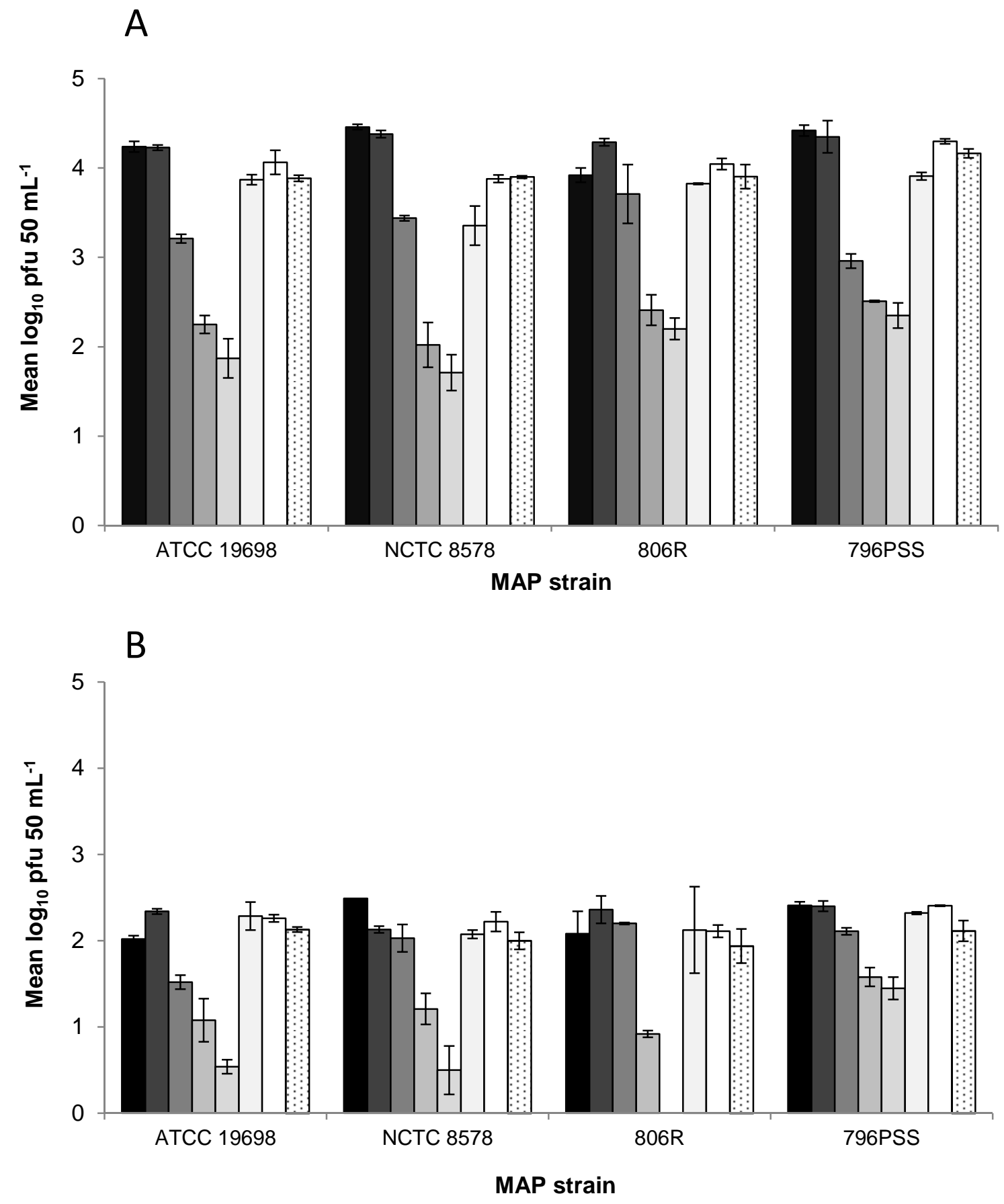